\title{
Inclusão escolar de sujeitos com deficiência visual na rede regular de ensino brasileira: revisão sistemática
}

\author{
José Carlos Leitão \\ Universidade de Tras-os-Montes e Alto Douro \\ Cleonice Terezinha Fernandes \\ Universidade de Cuiabá
}

\section{Resumo}

A revisão sistemática é um importante processo metodológico que faz a síntese dos estudos acerca de determinado tema, bem como mostra as lacunas para possíveis investigações. 0 presente estudo teve como objetivo revisar a literatura sobre estudos na área da inclusão de sujeitos com deficiência visual na rede regular de ensino brasileira. Foram utilizados descritores em língua portuguesa: "inclusão na educação", "educação inclusiva”, "deficiência visual”, "deficientes da visão", "educação dos cegos", e encontradas 452 publicações em bases de dados eletrônicas, lista de referências e comunicação pessoal. Após avaliação, 11 estudos preencheram os critérios de inclusão. A revisão revelou: um reduzido número de artigos que discute metodologias de ensino e estudos experimentais; predominância de estudos de caso e descritivos, com ênfase na mostra dos serviços e percepção dos profissionais; inúmeras variáveis passíveis de futuras investigações; e maior concentração de pesquisas sobre políticas públicas de inclusão na região sudeste do Brasil.

Palavras-chave: Educação inclusiva. Deficiência visual. Ensino aprendizagem especiais. Revisão sistemática. 


\section{Visual impairment and inclusion in Brazil: a systematic review}

Systematic review is an important methodological process that summarizes studies on a particular theme, and shows the gaps for possible investigations. In this sense, the purpose of this study is to analyze, by means of a systematic review, the literature on studies in the area of inclusion of persons with visual impairment in mainstream education in Brazil. The key-words were: "inclusion in education", "inclusive education", "visual impairment", "visually impaired", "education of the blind." Four-hundred and fifty-two publications were found, in electronic databases, reference lists and personal communication. After evaluation of the studies, eleven fulfilled the criteria for inclusion in this systematic review. The systematic revealed: a reduced number of articles discussing teaching methodologies and experimental studies; the predominance of descriptive studies and case studies, with an emphasis on describing services and the perception of professionals; numerous variables that merit future investigations; lastly this review showed that the majority of studies on inclusion policies focused on southeastern Brazil.

Keywords: Inclusive education. Visual impairment. Special education. Systematic review.

\section{Inclusión de sujetos con deficiencia visual en la enseñanza regular brasileña: revisión sistemática}

La revisión sistemática es un importante proceso metodológico que hace una síntesis de los estudios alrededor de determinado tema, como también apunta carencias para posibles investigaciones. El presente estudio tuvo como objetivo revisar la literatura sobre estudios en el área de inclusión de sujetos con deficiencia visual en la red regular de la enseñanza brasileña. Utilizamos descriptores en lengua portuguesa: "inclusión en la educación”, “educación inclusiva”, “deficiencia visual”, “deficientes de la visión”, “educación de ciegos"; encontramos 452 publicaciones, en bases de datos electrónicos, lista de referencias y comunicación personal. Después de la evaluación, 11estudios rellenaron los criterios de inclusión. La revisión reveló: un reducido número de artículos que discuten metodologías de enseñanza y estudios experimentales; predominancia de estudios de caso y descriptivos, con énfasis en la muestra de las labores y percepción de los profesionales; innumerables variables que pueden llegar a ser futuras investigaciones; y mayor concentración de investigaciones sobre políticas públicas de inclusión en la región sudeste de Brasil.

Palabras clave: Educación inclusiva. Deficiencia visual. Enseñanza aprendizaje especiales. Revisión sistemática. 


\section{Introdução}

O conceito de deficiência visual considerado no presente estudo abrange dois tipos: a cegueira e a baixa visão (Brasil, 2001). A cegueira caracteriza-se, segundo Martín e Ramirez (2003), pela total ausência de visão ou a simples percepção de luz; segundo os mesmos autores, vários países ocidentais consideram que um olho é cego quando seu campo visual se encontra reduzido a $20^{\circ}$.

A baixa visão é a alteração da capacidade funcional da visão, decorrente de inúmeros fatores isolados ou associados tais como: baixa acuidade visual significativa, redução importante do campo visual, alterações corticais e/ou sensibilidade aos contrastes que interferem ou limitam o desempenho visual do indivíduo (Brasil, 2001). As inúmeras causas que provocam a redução da acuidade visual também levam a diferentes situações de ordem funcional da visão, que mobilizam infinitas maneiras de ver. Devido tal diversidade, o conceito de deficiência visual, doravante denominada DV, traz a necessidade de partir de uma avaliação funcional da visão, cuja perspectiva educacional considera com DV todas as pessoas que não têm acuidade visual, ou que tenham problemas visuais graves não solucionáveis com recursos ópticos comuns.

É de extrema importância para a aprendizagem e desenvolvimento de cada aluno com DV a compreensão, por parte dos educadores envolvidos, do modo como cada um se organiza e o entendimento do que realmente conseguem fazer mediante sua condição visual. Para fins legais e administrativos, a oftalmologia classifica uma pessoa como cega se a sua acuidade visual for da ordem de 20/200 na escala optométrica decimal - tabela de Snellen', no melhor olho, mesmo com correção óptica adequada (Lavarda; Bidarra, 2007).

0 processo educacional de pessoas com baixa visão se dá por meios visuais e com o apoio de recursos específicos, que viabilizam a eficiência visual, tanto por meio de recursos ópticos como de não ópticos. Esses últimos são providências que modificam o ambiente e a postura da pessoa em torno da melhor realização de atividades acadêmicas e consta, entre outros, de: ampliações; controle de iluminação, visores e filtros (Brasil, 2001).

Em relação aos cegos, tem-se o uso universal do Sistema Braille como demarcador conceitual entre esses indivíduos e aqueles considerados com baixa visão. Os cegos são, portanto, aqueles cuja visão de perto é insuficiente para a vida escolar e leituras em geral, necessitando do uso do Sistema Braille.

6. A tabela de Snellen é composta de letras aleatórias, dispostas em fileiras, em tamanhos diferenciados, destinadas a medir a acuidade visual para longe. Cada fileira é designada por um número legível para um olho saudável padrão à distância medida em pés. A visão normal (20/20) indica a distância de 20 pés $(6 \mathrm{~m})$ em que a pessoa pode ler o tamanho 20. 
Para a Organização das Nações Unidas (ONU, 2002) e a Organização Mundial de Saúde (OMS) o número de pessoas com deficiência existentes em uma determinada cidade ou região é estimado em $10 \%$ da população. De acordo com o mesmo órgão, em torno de $0,05 \%$ da população possui deficiência visual grave - baixa visão e cegueira, sendo que esse percentual poderia chegar a $1 \%$ em países subdesenvolvidos. Com base nessas estimativas, o número de sujeitos com deficiência visual no Brasil se situaria entre 800 mil e 1,6 milhão de pessoas. Todavia, segundo o IBGE (Instituto Brasileiro de Geografia e Estatística, 2009), nos dados do censo demográfico realizado em 2000, 0 percentual de pessoas consideradas com pequena ou grande dificuldade permanente de enxergar é de quase $10 \%$ da população, enquanto os cegos somam $0,1 \%$ da população. Uma das dificuldades para a precisão de tais dados é que nos levantamentos demográficos, como no caso do censo de 2000, o próprio informante se autodefinia portador ou não de alguma deficiência (Brumer; Pavei; Mocelin, 2004). Conforme estudos do Centro de Políticas Sociais da Fundação Getúlio Vargas (CPS/FGV, 2003), a escolaridade média das pessoas que possuem alguma deficiência é menor que daquelas que não a possuem.

Definida a população considerada com deficiência visual, cabe iniciar a discussão sobre o conceito de inclusão. Do verbo incluir, do latim includere, no seu sentido etimológico significa fazer parte ou participar de. 0 conceito de referência do presente estudo implica no desenvolvimento de políticas, culturas, práticas que minimizem os obstáculos para a aprendizagem e contribuam para o aumento da participação dos alunos dentro e fora da escola, portanto vai além da convivência física inevitável no mesmo espaço (Santos, 2003). Fica implícita a ideia de que a inclusão é um processo bilateral, "pelo qual a sociedade se adapta para poder incluir, em seus sistemas sociais gerais, pessoas com necessidades educacionais especiais e, simultaneamente, estas se prepararam para assumir seus papéis na sociedade" (Sassaki, 1997, p. 41).

No âmbito da recomendação do MEC, a clientela passível de inclusão é bastante ampla. $\mathrm{O}$ documento dos PCNs - Parâmetros Curriculares Nacionais brasileiros optou por utilizar a designação adotada no ocidente: PNEEs - Pessoas com Necessidades Educativas Especiais; cujo universo compreende um alunado que inclui pessoas:

Com condições físicas, intelectuais, sociais, emocionais e sensoriais diferenciadas; com deficiência e altas habilidades; trabalhadoras ou que vivem nas ruas; populações distantes ou nômades; minorias lingüísticas, étnicas e culturais; e àqueles pertencentes a grupos desfavorecidos ou marginalizados. (Brasil, 1999, p. 23).

A inclusão como movimento social iniciou-se nos países desenvolvidos em meados da década de 1980. No Brasil, tomou impulso na década de 1990, com a difusão das ideias 
da Declaração de Salamanca, uma carta de intenções, que reafirma em nível internacional o compromisso de educação para todos, assinada por 92 países, dentre os quais - Brasil, como resultado da Conferência Mundial sobre Necessidades Educacionais Especiais, patrocinada pelo governo espanhol e pela UNESCO, ocorrido em Salamanca/ Espanha, em 1994. Tal declaração é tida como "o mais importante marco mundial na difusão da filosofia da educação inclusiva” (Mendes, 2006, p. 7).

No entanto, o marco legal brasileiro da oficialização dos princípios inclusivos na educação é a Constituição Federal de 1988, que expressa que a "educação dos portadores de deficiência deve se dar preferencialmente na rede regular de ensino" (Art. 277); também trata da criação de programas de prevenção, atendimento especializado, remoção de barreiras arquitetônicas, entre outros.

Em 1996, ocorre a promulgação da Lei de Diretrizes e Bases da Educação Nacional (LDBEN) no 9394, com um capítulo específico para a Educação Especial: o capítulo V, nos artigos 58, 59 e 60. Vale lembrar, entretanto, que a LDB de 1971 mencionava entre seus objetivos o de integrar as crianças "excepcionais a sociedade ${ }^{2 "}$. Portanto, os anos 1990 são marcados pelo advento da educação inclusiva. Em 2001 as Diretrizes Nacionais para a educação especial na educação básica estabelecem parâmetros para a organização dos serviços de educação especial numa perspectiva inclusiva (Conselho Nacional de Educação, 2001).

Decorridos 30 anos dessa política denominada na literatura especializada de integração escolar, até 1999 o que se viveu na prática, para além do discurso, foi o fortalecimento do processo de exclusão daquelas crianças consideradas indesejadas na escola regular, sobretudo na escola pública, que terminavam sendo encaminhadas para a classe especial (Bueno, 1993). Segundo Mendes (2006), no Brasil nunca aconteceu a almejada inserção na classe comum com a manutenção do contínuo de serviços de apoio para as crianças ditas especiais (Mendes, 2006, p. 7).

De acordo com os resultados do censo escolar do INEP (2009) houve um decréscimo nas matrículas em classes especiais ou escolas exclusivas em todas as regiões do país em relação a 2008, com destaque para o maior e menor índice respectivamente nas regiões sul ( $41 \%$ ) e sudeste (6\%). Segundo o referido censo (2009), atualmente o Brasil tem o registro de 252.687 matrículas em classes e/ou escolas exclusivas, demonstrando um percentual de queda de $21 \%$ em relação a 2008. É importante destacar o número de escolas exclusivas no país na ordem de 5.590 em 2009, numa diminuição

2. Todavia, desde a década de 1970 houve uma ampliação do acesso da população em geral à escola brasileira, e ocorreu a produção do fenômeno que ficou conhecido como fracasso escolar, um dos principais responsáveis pela implantação das classes especiais nas escolas básicas públicas do país (cf. Ferreira, 1994). 
de $16,6 \%$ em relação a 2008. As matrículas consideradas inclusivas totalizam 387.031 em 2009, marcando um aumento de $3 \%$ no país. 0 mesmo censo escolar do INEP (2009) registra, no entanto, uma redução das matrículas de alunos especiais em escolas regulares na região sul $(8 \%)$ e no centro-oeste ( $4 \%)$. 0 aumento mais significativo de matrículas inclusivas foi na região nordeste $(12 \%)$.

Uma análise numa perspectiva empírica, segundo Mendes (1999), permite constatar no Brasil uma prática do que a autora chama de inclusão total, entendida como a inserção de todos os sujeitos com alguma deficiência, independente do tipo e grau de limitação, na classe regular por tempo integral e sem qualquer outro tipo de apoio. Atualmente, a julgar pelas ações que vêm sendo tomadas pelas últimas gestões da Secretaria de Educação Especial do Governo Federal (SEESP), as mesmas são mais fundamentadas no princípio da inclusão total (Mendes, 2006).

Para Masini (2004, p. 31), há discordância quanto à efetividade da inclusão indiscriminada, na qual “sem qualquer avaliação prévia, a criança com deficiência é matriculada na escola regular, sem análise de suas condições e das necessidades requeridas para seu atendimento". As condições referidas pela autora dizem respeito às chamadas adaptações curriculares, ou seja, tanto a recursos humanos quanto possíveis adaptações físicas e/ou pedagógicas. A esse respeito, encontramos uma análise em Mendes (2006) sobre a existência de professores "inclusionistas" e "inclusionistas totais": para o primeiro tipo, o objetivo principal da escola é a conquista de habilidades acadêmicas específicas para a vida, enquanto que para o inclusionistas totais a finalidade principal é a socialização. Os inclusionistas defendem a manutenção do contínuo de serviços de apoio, entendendo que a capacidade da escola regular é finita, enquanto que os totais pregam inclusive a extinção dos serviços de apoio e acreditam na capacidade de reinvenção da escola dentro do sistema vigente, a fim de acomodar toda a diversidade humana. Ainda conforme Mendes (2006), o ideal seria a preservação do contínuo de serviços de apoio para que fosse salvaguardada a escolha daquele modelo que se mostrar mais eficiente e menos restritivo para cada situação. Há uma tendência na literatura especializada para entender que cada caso de inclusão, dada as suas particularidades, não se constitui em modelo passível de generalização.

Uma vez caracterizada a população com deficência visual, definido o conceito de inclusão adotado neste estudo, e feita apresentação dos dados demográficos e educacionais específicos deste grupo populacional, é necessário considerar o impacto social que a falta de visão provoca nas atitudes e crenças das pessoas. Tal impacto é derivado do imaginário coletivo, presente nos mitos familiares e sociais que revelam o modo como a pessoa com DV é vista por aqueles que enxergam e o lugar que ela ocupa no discurso dominante. 
Ainda nos tempos atuais as crenças populares e místicas sobre a cegueira permanecem vivas, bem como respectivos estereótipos. Como ilustra Amiralian:

[...] muitas e muitas estórias recheiam nossa memória com conceitos, noções e imagens mentais de cegueira, que, na maioria das vezes, refletem muito mais conceitos metafóricos e simbólicos de cegueira do que uma real experiência com pessoas cegas (Amiralian, 1997, p. 23)

Em Gonçalves, Leitão e Santos (2009) se encontra uma definição de estereótipo como estruturas cognitivas formadas pelos conhecimentos e expectativas acerca de outras pessoas, compartilhadas por indivíduos pertencentes a determinado grupo, sobretudo em função da categoria social a que tais pessoas pertencem. Para os referidos autores, os estereótipos apresentam custos cognitivos e sociais tanto para o percepecionador social quanto para quem é o alvo da percepção. Acabam por influenciar os comportamentos de quem vê mediante quem é visto, correspondendo ou não à realidade. No estudo em questão ficou evidente que há um comprometimento dos estereótipos sociais acerca da DV, que limitam, sobretudo, a relação entre escola inclusiva e aluno, na condição que se encontram atualmente, imersos numa cultura onde "ver é sinônimo de conhecer" (Masini, 2004, p. 76).

Portanto, é preciso pensar que os conceitos de saúde, normalidade, eficiência e os respectivos antônimos são construções histórico-sociais, que, infelizmente não se corrigem simplesmente pelo uso bem comportado da linguagem (Brumer; Pavei; Mocelin, 2004).

\section{Sobre os procedimentos da pesquisa}

As perguntas iniciais básicas dessa revisão sistemática sobre inclusão de sujeitos com DV foram as seguintes: Será que existe preocupação em aferir o desempenho acadêmico dos alunos com DV em relação aos seus pares que enxergam? Há algum questionamento ao imperativo moral da inclusão? Há registro de evidências empíricas que sustentam a inclusão?

Assim, essa revisão teve como objetivo inicial verificar se há estudos que avaliam o estado da inclusão de pessoas com DV e que buscam sobretudo traduzi-las em números e ideias sobre o desenvolvimento acadêmico dessa população. A busca foi realizada em bases de dados eletrônicas - Scielo, BBE/INEP e Latindex, lista de referências dos artigos identificados e comunicação pessoal. As referências que corresponderam aos critérios de inclusão foram avaliadas, independentemente do periódico. 
Foram considerados os seguintes descritores para localização dos artigos somente em língua portuguesa: "inclusão na educação”, "educação inclusiva”, "deficiência visual”, “deficientes da visão”, “educação dos cegos”. Recorreu-se aos operadores lógicos "AND", “OR" e "AND NOT" para combinação das referidas palavras-chave e termos utilizados para rastreamento das publicações. Por meio deste procedimento de busca, inicialmente foram identificados 452 publicações potencialmente passíveis de inclusão. Em seguida, identificaram-se somente aquelas que atenderam aos seguintes critérios de inclusão ${ }^{3}$ : al Somente artigos sobre pessoas com deficiência sensorial da visão (cegos e com baixa visão); b) Estudos restritos ao Ensino Fundamental e Médio; c) Estudos oriundos de pesquisas empíricas, ou seja, artigos originais de pesquisas acerca de vivências com alunos incluídos no ensino regular; d) Pesquisas relacionadas a grupos ou pesquisadores individuais ligados à Instituições de Ensino Superior (IES); e) Estudos realizados no Brasil; f) Publicações relativas ao período 2004 a 2009.

Após a primeira análise, que consistiu na avaliação dos 452 títulos, 79 foram considerados elegíveis para a segunda fase desta revisão, que tratou da leitura dos resumos. Após avaliação dos resumos, os estudos que pareciam preencher os critérios de inclusão foram lidos na íntegra. Ao final, onze (11) artigos atenderam a todos os critérios de inclusão. Na avaliação dos artigos, foram observados os seguintes aspectos: a) número de pesquisados; b) região (cidade/estado); c) tipo de instrumento utilizado na pesquisa; d) vínculo dos pesquisadores com a IES; el categorização dos resultados; f) considerações complementares.

\section{Resultados}

Na Tabela 1 da página a seguir, é apresentada a incidência dos onze (11) estudos de acordo com as regiões do Brasil, num total de trezentos e vinte (320) sujeitos pesquisados, incluindo um artigo com "N" (não revelado). Nenhum estudo utilizou procedimentos estatísticos, de modo que esta revisão não consta de meta-análise, método estatístico usado em revisões sistemáticas para integrar os resultados dos estudos incluídos (Castro, 2001).

A composição das amostras variou quanto à faixa etária, justamente porque se refere à inclusão no ensino fundamental e médio; algumas pesquisas foram realizadas após a idade adulta do indivíduo, para além da situação em que muitos alunos com

3. Foram excluídas pesquisas referentes a: alunos com dupla ou múltipla deficiência; sujeitos incluídos no Ensino Superior; artigos caracterizados como revisões bibliográficas. 
necessidades especiais são incluídos com defasagem idade/ano escolar. Também há outros motivos da disparidade etária: pesquisas que avaliam o professor, a coordenação/direção da escola, representantes de instituições e pessoas adultas associadas a instituições de apoio a pessoas com DV.

Tabela 1 - Incidência dos estudos de acordo com as regiões - 2004 a 2009

\begin{tabular}{|l|c|c|}
\hline Região & N (\%) & Estudos* (\%) \\
\hline Sudeste & $202(63 \%)$ & $5(45,5)$ \\
\hline Norte & $53(16,5 \%)$ & $1(9 \%)$ \\
\hline Sul & $48(15,5 \%)$ & $4(36,5 \%)$ \\
\hline Nordeste & $17(0,5 \%)$ & $1(9 \%)$ \\
\hline
\end{tabular}

*Número de estudos por região. Fonte: autores (2011).

Quadro 1 - Estudos segundo os instrumentos e síntese dos resultados - 2004 a 2009

\begin{tabular}{|l|l|l|}
\hline Referência & Instrumento & Síntese dos resultados \\
\hline $\begin{array}{l}\text { Brumer; Pavei; Mocelin } \\
\text { (2004) }\end{array}$ & Entrevista & $\begin{array}{l}\text { Aumento de vagas/ } \\
\text { insuficiência de profissionais }\end{array}$ \\
\hline Golin; Bastos (2004) & Entrevista/Depoimentos & $\begin{array}{l}\text { Métodos e estudos } \\
\text { inadequados }\end{array}$ \\
\hline Silva (2006) & Estudo de Caso & $\begin{array}{l}\text { Poucas condições para } \\
\text { participação ativa do aluno DV }\end{array}$ \\
\hline $\begin{array}{l}\text { Maciel; Rodrigues; Costa } \\
\text { (2007) }\end{array}$ & Questionário/Entrevista & $\begin{array}{l}\text { Maioria profs. não } \\
\text { especializados: respostas } \\
\text { inatistas e } \\
\text { comportamentalistas }\end{array}$ \\
\hline Lavarda; Bidarra (2007) & Observação de Aulas & $\begin{array}{l}\text { Uso excessivo de dêiticos } \\
\text { em sala de aula }\end{array}$ \\
\hline Dall'Acqua (2007) & Observação Participante & $\begin{array}{l}\text { Atuação do professor } \\
\text { itinerante é efetiva }\end{array}$ \\
\hline
\end{tabular}

4. Dêixis, palavra importada do grego antigo deíknymi, significa ação de mostrar. Para Lavarda e Bidarra (2007) é contexto que inclui elementos externos ao enunciado: gestos, expressões faciais, entre outros.

5. Atendimento itinerante é "uma modalidade especializada de apoio pedagógico; desenvolvida por profissional devidamente capacitado, se caracteriza pela movimentação do professor, que se deslocará para as escolas do ensino regular onde existir matriculados alunos com deficiência visual" (Brasil, 2001, p. 106). 
Quadro 1 - continuação

\begin{tabular}{|l|l|l|}
\hline Referência & Instrumento & Síntese dos resultados \\
\hline Taveira (2008) & $\begin{array}{l}\text { Grupos Focais/ Análise de } \\
\text { Conteúdo }\end{array}$ & $\begin{array}{l}\text { Alunos “encarteirados" } \\
\text { (termo análogo a cárcere) }\end{array}$ \\
\hline Rocha; Almeida (2008) & Entrevista Semi-Estruturada & $\begin{array}{l}\text { Falta de planejamento ao } \\
\text { serviço itinerante }\end{array}$ \\
\hline Fernandes; Healy (2009) & $\begin{array}{l}\text { Método de Dupla } \\
\text { Estimulação (Vygotsky) }\end{array}$ & $\begin{array}{l}\text { Bons resultados pelo uso } \\
\text { funcional do sistema háptico } \\
\text { (tato ativo) }\end{array}$ \\
\hline Laplane (2006) & Observação e Anamnese & $\begin{array}{l}\text { Atividades grupais como } \\
\text { estimulantes da } \\
\text { aprendizagem }\end{array}$ \\
\hline $\begin{array}{l}\text { Maruyama; Sampaio; } \\
\text { Rehder (2009) }\end{array}$ & $\begin{array}{l}\text { Survey Descritivo e } \\
\text { Documental }\end{array}$ & $\begin{array}{l}\text { Falta de conhecimento } \\
\text { técnico sobre DV }\end{array}$ \\
\hline
\end{tabular}

Fonte: autores (2011).

Quanto aos instrumentos utilizados para coleta de dados, verificou-se que todos constituem-se de pesquisas qualitativas: estudos de caso, entrevistas, observações das aulas, das falas dos professores, dos canais sensoriais, depoimentos, análise de conteúdo, série de entrevistas individuais e com grupos focais, análise da história de desenvolvimento e aprendizagem. Também se destaca uma pesquisa com questionário - Survey descritivo e documental (Maruyama; Sampaio; Rehder, 2009) e uma que aplicou o método da Dupla Estimulação de Vigotsky (Fernandes; Healy, 2008) que inclui, entre outros procedimentos, diálogos baseados em tarefas. É importante ressaltar, nesta última pesquisa, que tais tarefas são pretensamente propostas muito além da capacidade e dos conhecimentos do pesquisado, onde se cria uma situação estruturada e o sujeito recebe uma orientação ativa, sendo estimulado a construir uma estratégia que ainda não possui (Fernandes; Healy, 2008).

\section{Discussão}

0 debate sobre inclusão vem crescendo em número nas pesquisas atuais, cujo motivo principal é: o aumento da própria expectativa dos pais e mães, por meio da escolarização da população ou ainda pelas ações sensibilizadoras das políticas públicas e da retórica midiática atual. Todavia, tais investigações ainda são em número pouco expressivos em relação às demais temáticas educativas e tratam, em sua maioria, de revisões teóricas, o que justifica o reduzido número de artigos com pesquisas empíricas encontradas na busca para a presente revisão sistemática. 
Apesar do contexto atual e do discurso, a inclusão ainda é um assunto cercado de mitos os quais pretendemos discutir neste estudo. Dada as dimensões continentais do Brasil, e seu desenvolvimento regional desigual, há ainda quem acredite que o que move a inclusão é a inexistência de espaços específicos para esta clientela, e que pessoas com DV teriam impedimentos para frequentar escolas. Também há o desconhecimento de que o Sistema Braille seja um meio acessível e universal de escrita, inclusive para quem não é cego, bem como a crença de que o domínio do mesmo significa que seus usuários são portadores de superpoderes ou talentos especiais.

A ausência de estudos empíricos que discutem metodologias de ensino e buscam analisar a capacidade cognitiva de sujeitos com DV incluídos é um ponto importante a ser considerado e uma lacuna a ser preenchida em futuras investigações. A revisão mostrou ainda um número insuficiente de pesquisas voltadas para o desenvolvimento de programas ou estudos experimentais. Dentre os publicados, predominam os estudos de casos e descritivos, com ênfase maior para a mostra dos serviços existentes, que geralmente incluem a opinião dos profissionais envolvidos.

Se por um lado a diversidade de metodologias de pesquisa foi um impedimento para uma análise estatística macro, com o uso da meta-análise, por outro lado revelaram inúmeras variáveis passíveis de investigação, constituintes de perspectivas para futuras pesquisas, como: o uso de dêixis - contexto extra-verbal nas aulas; desempenho acadêmico comparativo e longitudinal; propostas inovadoras de adaptação de materiais, atividades de desenvolvimento sensorial; metodologias ativas de ensino aprendizagem; atividades grupais integradoras entre sujeitos com e sem acuidade visual; além de estudos baseados em ressonância magnética funcional para mapear a atividade/ funções no córtex cerebral de indivíduos com deficiênciab.

Vale ressaltar que estudos atuais mostram que pacientes com cegueira adquirida antes dos 14 anos não apresentam alterações estruturais na ressonância magnética encefálica (RME) quando comparados com o grupo de voluntários. No estudo de Piovesan et al. (2002), imagens de RME não demonstraram alterações no córtex occipital dos cegos em relação a voluntários com acuidade visual normal.

Apesar de não haver pesquisas cujo levantamento de dados foi feito com bases nacionais, a inclusão é vista nacionalmente de forma positiva, sobretudo pelos pesquisadores das IES, ou ainda como um espaço promissor de oportunidade ao desenvolvimento dos indivíduos com deficiência e uma interessante fonte de pesquisa sobre a

6. FMRI - do inglês functional magnetic resonance imaging - técnica de aquisição e análise de imagens do cérebro por meio de ressonância magnética, ou Ressonância Magnética Encefálica (RME). É feita com intuito de se detectar áreas de actividade cortical relacionadas a um determinado estímulo ou tarefa, de forma segura, eficaz e não invasiva. 
diversidade da capacidade cognitiva humana. Neste aspecto, a pesquisa de Fernandes e Healy (2008) revelou, entre outros: a capacidade de indivíduos sem acuidade visual em compreender conceitos matemáticos mais elaborados. A questão levantada pelas autoras é que tais conceitos devem ser viabilizados por sistemas mediadores adequados, diálogo e ferramentas materiais manipulativas, centrados nas habilidades dos sujeitos e não na deficiência, fazendo destaque ao sistema háptico - tato ativo e estimulação de habilidades potenciais a partir de atividades provocadoras de situações que oportunizem a elaboração de conceitos pelo sujeito, que ainda não os possui. $\mathrm{Na}$ pesquisa de Lavarda e Bidarra (2007), os autores discutem o uso natural e excessivo de dêiticos em aulas expositivas de classes regulares, entendidos como o contexto extra-verbal da comunicação, que faz com que os alunos com DV fiquem expostos a ambíguos espaços vazios de fala, incapazes de serem preenchidos pela restrição impeditiva da falta de visão, caso não se faça uma referência oral simultânea.

Portanto, um desafio para os pesquisadores da área é estudar a capacidade cognitiva, destacando o caráter particular de cada caso. Deverá haver contribuições que discutirão a qualidade das atividades de desenvolvimento sensorial, adequadas à aprendizagem de cada aluno em particular. Nesse sentido, destaca-se a proposta de atividades úteis e integradoras para e com todos os alunos na classe, analisada na presente revisão sistemática, que traz, por exemplo, os jogos grupais adaptados citados na pesquisa de Laplane e Batista (2008), ambas professoras doutoras da UNICAMP?

Para finalizar, julga-se interessante o destaque de pesquisas diagnósticas e prognósticas de casos de inclusão em geral, não apenas de DV, em estados ou cidades, bem como de análise de políticas públicas respectivas. Neste conjunto encontram-se os trabalhos de Masini (2004), que estudou uma escola da rede municipal de ensino de São Bernardo do Campo-SP; Bruno (2007), que apresenta estatísticas da formação de professores nas licenciaturas, específica para a inclusão; Marins e Matsukura (2009) com uma pesquisa sobre a implementação de ações para inclusão nas cidades-pólo do estado de São Paulo; Pletsch, Fontes e Glat (2006) que discutem a inclusão na rede de ensino do município do Rio de Janeiro, a maior rede municipal de Educação da América Latina, onde 1054 escolas, com mais de setecentos mil alunos matriculados, englobam 8.869 alunos com necessidades especiais; Mendes (2008), que realizou um levantamento das políticas públicas vigentes no país a partir da revisão da agenda de um grupo de pesquisa sobre inclusão escolar da Universidade Federal de São Carlos - UFSCar,

7. Na análise dos títulos dos artigos selecionados para essa revisão sistemática, nos deparamos com uma maior concentração de pesquisas sobre políticas públicas e experiências sobre inclusão na região sudeste do país, com destaque para o estado de São Paulo, independentemente das áreas das deficiências. 
no qual encontram-se dissertações, teses, pesquisas de iniciação científica e projetos de grande porte; Sassaki (2004), que relata a experiência enquanto consultor da implantação de uma rede inclusiva no Estado de Goiás entre 1999 e 2002; Alves (2008), que avalia 45 professores não-especializados da rede pública inclusiva do Estado de São Paulo, nos ensinos Fundamental e Médio; Siems (2008), que pesquisou a representação social/identidade docente de professoras que atuam exclusivamente na rede especial do Estado de Roraima; e Laplane (2006), que analisa as políticas de educação inclusiva comparativamente entre Brasil e Inglaterra. Nessa última pesquisa, Laplane (2006), ao analisar as redes de ensino do Brasil e da Inglaterra, insere-as em um movimento de características excludentes, que tem afetado a sociedade ocidental desde o período pós Segunda Guerra. Segundo a autora, apesar do amparo legal existente em ambos os países, a prática da inclusão esbarra tanto nos conflitos e tensões geradas pelas condições sociais gerais quanto pelos sistemas educacionais.

Mediante o exposto, acredita-se que, no caso do Brasil, há um impedimento ainda maior para a construção de uma rede inclusiva afirmativa, pois se trata de um país produtor de uma enorme desigualdade social, "fruto de uma das piores sistemáticas de distribuição de renda do planeta" (Mendes, 2006, p. 12).

Em suma, o que se observou nessa revisão sistemática é que a solução alternativa passa necessariamente pelo cuidado com aspectos individuais, e análise multidimensional de cada realidade - escola, bairro, instituição; dependerá da adesão de todos os envolvidos e conterá preferencialmente formação prévia e continuada dos professores. A escola estará constantemente em aprendizado, devido à natureza das especificidades e dinamicidade da inclusão, bem como dos avanços esperados às pesquisas nesse campo. É urgente que as políticas adotadas enxerguem aqueles sujeitos que não aprendem na escola, mas efetivamente por intermédio da ação direta de seus pais, professores particulares, ou ainda, quando estes são inexistentes, recorrem à autoexclusão, entendida como desestímulo pessoal, ou, numa perspectiva liberal, vista como falta de esforço do indivíduo. Isto fará com que percebamos que, afinal, a prática atual possível no Brasil não é da inclusão total.

Considera-se que o sistema político brasileiro ainda precisa tornar a prática coerente com seu discurso legal. Durante a presente revisão se constatou que as principais características do modelo de inclusão adotado no Brasil são: a dicotomização entre educação inclusiva e inclusão total; a interpretação de que a educação inclusiva é algo que diz respeito exclusivamente à população tradicional da educação especial e não ao conjunto dos excluídos; e a influência de juristas nas definições das políticas para sujeitos com necessidades educacionais especiais, cuja tomada de decisões são pouco ou nada pautadas na sustentação empírica fornecida pelas pesquisas científicas 
(Mendes, 2006). Mendes (2006) considera um importante exercício para a pesquisa científica buscar quais as práticas necessárias à inclusão de pessoas com deficiência e quaisquer outras necessidades especiais, bem como quais os conhecimentos necessários para fundamentar tais práticas. Disparidades regionais importantes devem ser minimizadas, com estímulos a estudos justamente na região centro-oeste do Brasil, região de origem de um dos autores do presente estudo.

É preciso superar uma educação que tem se mostrado atuar contra os ideais de inclusão social. Escolhemos as palavras de Mendes (2006) para finalizar a presente contribuição ao debate:

[...] a grande maioria dos alunos com necessidades educacionais especiais estão ainda em nosso país fora de qualquer tipo de escola. Alguns poucos estão inseridos em classes ou escolas especiais, ou se encontram ao acaso nas classes comuns das escolas públicas. Tal quadro indica muito mais uma exclusão escolar generalizada dos indivíduos com necessidades educacionais especiais na realidade brasileira, a despeito da recorrência no país da retórica da integração escolar e mais recentemente da educação inclusiva. (Mendes, 2006, p. 12)

\section{Referências}

ALVES, Maria Corrêa de Oliveira. Um estudo sobre a inclusão do aluno portador de necessidades educacionais especiais na rede pública do Estado de São Paulo. Monografia lespecialização Latu Sensul. Centro Federal de Educação Tecnológica - CEFET/SP, 2008.

AMIRALIAN, Maria Lúcia Toledo Moraes. Compreendendo o cego: uma visão psicanalítica da cegueira por meio de desenhos - estórias. São Paulo: Casa do Psicólogo, 1997.

BRASIL. Constituição 1988 - Constituição da República Federativa do Brasil. São Paulo: Atlas, 1988. Lei no. 9.394, de 20 de dezembro de 1996. Estabelece as Diretrizes e Bases da Educação Nacional. Diário Oficial [da República Federativa do Brasil], Brasília, DF, 23 de dez. 1996. Disponível em: <http://www.planalto.gov.br/ccivil_03/LEIS/L9394.htm>. Acesso em: 31 jul. 2009.

Parâmetros Curriculares Nacionais - Adaptações Curriculares. Secretaria de Educação Fundamental. Secretaria de Educação Especial. Brasília: MEC/SEF/SEESP, 1999.

Ministério da Educação. Secretaria de Educação Especial. Programa de Capacitação de Recursos Humanos do Ensino Fundamental: deficiência visual. Brasília: MEC/SEESP, 2001. (Série Atualidades Pedagógicas, 6, v.1)

BUENO, José Geraldo Silveira. Educação Especial Brasileira: integração/segregação do aluno diferente. São Paulo: EDUC/PUCSP, 1993.

BRUMER, Anita; PAVEI, Katiuci; MOCELIN, Daniel Gustavo. Saindo da "escuridão": perspectivas da inclusão social, econômica, cultural e política dos portadores de deficiência visual em Porto Alegre. Sociologias, n. 11, p. 300-327, jun. 2004. 
BRUNO, Marilda Moraes Garcia. Educação Inclusiva: Componente da formação de educadores. Revista Benjamin Constant, MEC, Rio de Janeiro, v. 13, n. 38, p. 10-17, dez. 2007.

CASTRO, Aldemar Araújo. Curso de Revisão Sistemática e Metanálise. São Paulo: LED-DIS/ UNIFESP 2001. Disponível em: <http://www.virtual.epm.br/cursos/metanalise/>. Acesso em: jun. 2009.

CPS/FGV - Centro de Políticas Sociais/Fundação Getúlio Vargas. Diversidade: retratos da deficiência no Brasil. Fundação Getulio Vargas e Fundação Banco do Brasil, 2003. Disponível em: <http://www.fgv. br/cps/deficiencia_br/index2.htm>. Acesso em: 30 jul. 2009.

CONSELHO NACIONAL DE EDUCAC̣ÃO (Brasil). Câmara de Educação Básica. Resolução no. 2, de 11 de setembro de 2001. Institui diretrizes nacionais para a educação especial na educação básica. Disponível em: <http://portal.mec.gov.br/index.php?option=com_content\&view=article\&id=12907:legislacoes \&catid=70:legislacoes $>$. Acesso em: 30 jul. 2009.

DALL'ACQUA, Maria Julia Canazza. Atuação de professores do ensino itinerante face à inclusão de crianças com baixa visão na educação infantil. Paidéia, Ribeirão Preto, v.17, n. 36, p. 115-122, abr. 2007. Disponível em: <http://www.scielo.br/pdf/paideia/v17n36/v17n36a11.pdf>. Acesso em: 22 out. 2009. DECLARAÇÃO DE SALAMANCA e linha de ação sobre necessidades educativas especiais. Brasília, DF: CORDE, 1994.

FERNANDES, Solange Hassan Ahmad Ali; HEALY, Lulu. A apropriação de noções sobre reflexão por aprendizes sem acuidade visual: uma análise vygotskyana. Revista de Educação \& Cultura Contemporânea. Disponível em: <http://www.emis.de/proceedings/pme28/pp/pp018_healy.pdf>. Acesso em: 22 jul. 2009.

GONÇALVES, Gabriela; LEITÃO, José Carlos; SANTOS, Joana. Gerir estereótipos: ao longo da vida: uma convivência difícil. In: MOREIRA, Maria Helena; GABRIEL, Ronaldo Calçada. Menopausa em Forma: Promoção do Exercício e da Saúde em Mulheres Pós-menopáusicas. Lisboa: Sociedade Portuguesa de Menopausa, 2009.

GOLIN, Andréa Feller ; BASTOS, Lia Caetano. Por uma educação inclusiva para portadores de deficiência visual: um novo olhar. Revista da Educação Especial, UFSM, Santa Maria, n. 24, p. 41-52, 2004. IBGE. Instituto Brasileiro de Geografia e Estatística. Disponível em: <http://www.ibge.gov.br/home/ estatistica/populacao/estimativa2008/default.shtm>. Acesso em: 31 jul. 2009.

INEP. Instituto Nacional de Estudos e Pesquisas Educacionais Anísio Teixeira. Resultados do Censo Escolar 2009 - Tabelas Brasil, regiões e Estados. Brasília, 2009. Disponível em: <http://www.inep.gov. br/imprensa/noticias/censo/escolar/news09_11.htm>. Acesso em: 01 dez. 2009.

LAPLANE, Adriana Lia Friszman. Uma análise das condições para a implementação de políticas de educação inclusiva no Brasil e na Inglaterra. Educação e Sociedade, Campinas, v. 27, n.96, p. 689715. 2006. Disponível em: <http://www.scielo.br/scielo.php?script=sci_arttext \&pid=\$0101-7330200 6000300004\&lng=en\&nrm=iso\&tlng=pt>. Acesso em: 22 jun. 2009.

.; BATISTA, Cecília Guarnieri. Ver, não ver e aprender: a participação de crianças com baixa visão e cegueira na escola. Cadernos CEDES, Campinas, v.28, n. 75, p. 209-227, maio-ago. 2008. Disponível em: <http://www.scielo.br/scielo.php?script=sci_arttext\&pid=S0101-326220 08000200005\& lng=pt\&nrm=iso $>$. Acesso em: 30 out. 2009.

LAVARDA, Santa Terezinha Falcade; BIDARRA, Jorge. A dêixis como um "complicador/facilitador" no contexto cognitivo e lingüístico em ambiente educacional face aos alunos com deficiência visual. Revista Brasileira de Educação Especial, Marília, v.13, n.3, p. 309-324, set.-dez. 2007 
MACIEL, Cristiane Vales; RODRIGUES, Rosinete dos Santos; COSTA, Arley José Silveira. A concepção dos professores do ensino regular sobre a inclusão de alunos cegos. Revista Benjamin Constant; MEC. Rio de Janeiro, v. 13, n.36, p 15-21, abr. 2007.

MARINS, Simone Cristina Fanhani; MATSUKURA, Thelma Simões. Avaliação de políticas públicas: a inclusão de alunos com necessidades educacionais especiais no Ensino Fundamental das cidadespolo do Estado de São Paulo. Revista Brasileira de Educação Especial, Marília, v. 15, n.1, jan. 2009. Disponível em: <http://www.scielo.br/scielo.php?script=sci_arttext\&pid=S1413-65382009000100005 \&lng=pt\&nrm=iso>. Acesso em: 22 jun. 2009.

MARTÍN, Manuel Bueno; RAMIREZ, Francisco Ruiz. Visão Subnormal. In: MARTíN, Manuel Bueno; BUENO, Salvador Toro (Org). Deficiência Visual: Aspectos Psicoevolutivos e Educativos. São Paulo: Santos, 2003. p 27-40.

MARUYAMA, Aparecida Tapia; SAMPAIO, Paulo Ricardo Souza; REHDER, José Ricardo Lima. Percepção dos professores da rede regular de ensino sobre os problemas visuais e a inclusão de alunos com baixa visão. Revista Brasileira de Oftalmologia, Rio de Janeiro, v. 68, n.2, mar. 2009. Disponível em: <http://www.scielo.br/scielo.php?pid=S0034-72802009000200002\& script=sci_arttext>. Acesso em: 22 jul. 2009.

MASINI, Elcie Aparecida Fortes Salzano. Uma experiência de Inclusão - providências, viabilização e resultados. Educar, Curitiba, n. 23, p. 29-43. 2004.

MENDES, Enicéia Gonçalves. Diretrizes e Parâmetros curriculares nacionais e a educação especial: inclusão ou exclusão da diversidade? In: BICUDO, Maria Aparecida; SILVA, Celestina Alves (Org). Formação do Educador: Avaliação institucional, ensino e aprendizagem. São Paulo: Editora UNESP. 1999. p 73-90.

A radicalização do debate sobre inclusão escolar no Brasil. Revista Brasileira de Educação, v. 11, n. 33, p. 387-405, dez. 2006.

Pesquisas sobre Inclusão Escolar: Revisão da Agenda de um Grupo de Pesquisa. Revista Eletrônica de Educação, São Carlos. UFSCar. 2008. Disponível em: <http://www.reveduc.ufscar.br/ index.php?option=com_content\&task=view\&id=46\&ltemid=48>. Acesso em: 20 jul. 2009.

ONU. Programa de ação mundial para as pessoas com deficiência. ONU, 2002. Disponível em: <http:// www.interlegis.gov.br/processo_legislativo/copy_of_20020319150524/20030623133227/2003062311 4443/view>. Acesso em: 30 out. 2009.

PIOVESAN, Elcio Juliato et al. Análise estrutural e funcional do córtex visual em pacientes cegos com perda visual antes dos 14 anos de idade. Arquivos de Neuro-Psiquiatria, São Paulo, v. 60, n. 4, p. 949953, dez. 2002. Disponível em: < http://www.scielo.br/scielo.php?script=sci_arttext \&pid=S0004282X2002000600011\&lang=pt>. Acesso em: 14 jul. 2009.

PLETSCH, Márcia Denise, FONTES, Rejane de Souza; GLAT, Rosana. 0 papel da educação especial no processo de inclusão escolar: a experiência da rede municipal de educação do Rio de Janeiro. Disponível em: <http://www.anped.org.br/reuni\%C3\%B5es/29ra/trabalhos/trabalho/GT15-2107-int.pdf>. Acesso em: 31 ago. 2009.

ROCHA, Margarette Matesco; ALMEIDA, Maria Amélia. Ensino itinerante para deficientes visuais: um estudo exploratório. Revista Brasileira de Educação Especial, Marília, v.14, n. 2, p 201-216, 2008. Disponível em: <http://www.scielo.br/scielo.php?script=sci_arttext\&pid=S1413-65382008000200005\&lng=pt\& nrm=iso>. Acesso 22 jul. 2009. 
SASSAKI, Romeu Kazumi. Inclusão: Construindo uma sociedade para todos. Rio de Janeiro: WVA, 1997. . Programa Estadual de Educação para a Diversidade numa Perspectiva Inclusiva no Estado de Goiás, Brasil. Superintendência de Ensino Especial da Secretaria de Educação do Estado de Goiás, 2004. Disponível em: <www.simposioestadopoliticas.ufu.br/imagens/anais/pdf/BP03.pdf>. Acesso em: 10 out. 2009.

SAMPAIO, Paulo Ricardo Souza. Contribuição para o tratamento da dislexia: o uso de lentes esferoprismáticas na leitura. São Paulo, 2003. Disponível em: <http://bases.bireme.br/cgibin/wxislind.exe/ iah/online/?IsisScript=iah/iah. $x i s \& s r c=g o o g l e \& b a s e=L I L A C S \& l a n g=p \& n e x t A c t i o n=\ln k \& e x-$ prSearch=406700\&indexSearch=ID>. Acesso em: 12 nov. 2009.

SANTOS, Monica Pereida dos. 0 papel do ensino superior na proposta de uma educação inclusiva. Revista da Faculdade de Educação, Rio de janeiro: UFF, n.7, p.78-91, 2003.

SIEMS, Maria Edith Romano. Educação especial em tempos de educação inclusiva: a identidade docente em questão. Linhas Críticas, Brasília, v.14, n.27, p. 209-226, 2008.

TAVEIRA, Cristiane Correia. Representaç̃oes Sociais de Professores sobre a inclusão de alunos com deficiência em turmas regulares. Revista Benjamin Constant/MEC, Rio de Janeiro, ano 14, n. 39, p. 10-19, 2008.

Recebida $2^{\text {a }}$ versão em abril de 2011

Aprovada $2^{a}$ versão em maio de 2011

José Carlos Leitão, doutorado em Ciências do Desporto, bacharel em Educação Física e Psicologia. Docente em Metodologias de Investigação e Estatística em Ciências do Desporto, Exercício e Saúde da Universidade de Trás-os-Montes e Alto Douro - UTAD, Portugal. Publicação recente: Young people's spare time. Family's representations (Revista Portuguesa de Ciências do Desporto, vol 10, n¹, 2010). E-mail: jcleitaodutad.pt.

Cleonice Terezinha Fernandes, doutoranda da Universidade de Trás-os-Montes e Alto Douro UTAD, Portugal e bolsista da FAPEMAT. Professora da Universidade de Cuiabá - UNIC e do Colégio Salesiano São Gonçalo numa classe inclusiva de deficiência visual. Publicação recente: Manual de Técnicas Operatórias para Pessoas com Deficiência Visual (MEC, 2009). E-mail: cleo_terezinha ahotmail.com 


\section{Linhas Críticas}

A revista foi criada em 1995 com o objetivo de divulgar a produção científica de docentes e pesquisadores da Universidade de Brasília, como também editar artigos de autores de outros centros de investigação do Brasil e do exterior. Conta, desde o início, com um Comitê e Conselho Editorial qualificado, reconhecido nacional e internacionalmente. A partir de 2005 o periódico passou a contar com uma versão online na REDALYC - Red de Revistas Científicas de América Latina y el Caribe, España y Portugal, disponível em: www.redalyc.com.

\section{NÚMEROS TEMÁTICOS}

No 33 (vol. 17) Educação especial inclusiva No 32 (vol. 17) Docência, formação e gestão No 31 (vol. 16) Hermenêutica, teoria crítica e educação No 30 (vol. 16) Educação profissional e tecnológica No 29 (vol. 15) Formação de profissionais da educação No 28 (vol. 15) Políticas educacionais e novas formas de regulação NNo 26 (vol. 14) Docência na educação superior No 24 (vol. 13) Educação e novas tecnologias No 22 (vol. 12) Educação, formação e aprendizagem No 21 (vol. 11) Edição comemorativa: 10 anos de Linhas Críticas No 20 (vol. 11) Políticas públicas para a educação No 18 (vol. 10) Gestão na educação No 17 (vol. 9) Novas tecnologias na educação No 16 (vol. 9) Educação especial No 15 (vol. 8) Criatividade na educação No 12 (vol. 7) Formação de professores e financiamento da educação No 7-8 ( vol. 4) Psicodrama na educação No 5-6 (vol. 3) Filosofia para crianças № 3-4 (vol. 2) Faculdade de Educação da UnB: um ideário pedagógico à altura do Brasil 